\title{
Effect of Chromium, Boron and Manganese Additions on the Deformation and Recrystallization Textures of Warm Rolled Low Carbon Steels
}

\author{
Mohammad R. TOROGHINEZHAD, Alan O. HUMPHREYS, ${ }^{1)}$ Elhachmi ESSADIQI, ${ }^{2)}$ \\ Fakhraddin ASHRAFIZADEH, Abbas NAJAFIZADEH and John J. JONAS ${ }^{1)}$ \\ Department of Materials Engineering, Isfahan University of Technology, Isfahan, 84154 Iran. \\ 1) Department of Metallurgical Engineering, McGill University, Montreal, Quebec, H3A 2B2 Canada. \\ 2) Materials Technology Laboratory, NRC CANMET, 568 Booth Street, Ottawa, Ontario, K1A 0G1 Canada.
}

(Received on December 9, 2002; accepted in final form on March 17, 2003)

\begin{abstract}
The effect of solute carbon content, as well as of chromium, boron and manganese addition, on the warm rolling behavior was investigated. Both the as-rolled and recrystallized microstructures and textures were assessed after rolling at temperatures between 440 and $780^{\circ} \mathrm{C}$. In an unalloyed low carbon (LC) steel, intense in-grain shear bands were formed at low rolling temperatures, but this intensity was drastically reduced at higher temperatures. Alloying with chromium and boron significantly enhanced the development of shear bands at the higher rolling temperatures. The intensities of the deformation textures produced were little changed with rolling temperature in the IF steel, but increased markedly with temperature for the LC grade. Conversely, the strength of the LC steel recrystallization texture decreased with increasing temperature. The addition of chromium to the low manganese steel somewhat strengthened the $\{111\}$ component of the annealing texture at the higher rolling temperatures. However, boron addition resulted in a retained rolling component and severely disrupted the recrystallization textures. A higher manganese level was also detrimental to the development of the ND fibre components. These differences are attributed to variations in the dynamic strain aging and precipitation behaviors of the various materials attributable to their differing alloy contents.
\end{abstract}

KEY WORDS: warm rolling; solute carbon; dynamic strain aging; shear bands; deformation texture; recrystallization texture.

\section{Introduction}

The practice of warm (ferritic) strip rolling, where steels are rolled at temperatures within the ferrite region $\left(600-850^{\circ} \mathrm{C}\right)$, is gradually becoming established, particularly for interstitial-free (IF) materials. ${ }^{1-3)}$ This practice offers commercial benefits to manufacturers as it can reduce production costs and broaden the product range. ${ }^{1)}$ These advantages impinge on all stages of the rolling process, from reheating, to rolling and pickling. ${ }^{4}$ In order to fabricate products for deep drawing applications, good formability is required, i.e. high mean $r$-value $\left(r_{\mathrm{m}}\right)$, and low planar anisotropy $(\Delta r)$. Thus the recrystallization texture formed during annealing must have a strong $\{111\}$ component. ${ }^{5)}$ Such a texture is usually produced when warm rolled IF sheets are recrystallized; however, when a warm rolled low carbon steel is annealed, only a weak $\{111\}$ texture is formed. It has been shown that in order to develop strong $\{111\}$ textures, shear bands must develop during rolling, the presence of which promotes the nucleation of recrystallized grains of this orientation. ${ }^{6}$ )

Shear bands constitute localized flow within a grain at a higher rate than in the bulk material; thus their appearance is strongly dependent upon the rate sensitivity of the material. IF steels display small positive rate sensitivities at warm rolling temperatures, ${ }^{7)}$ with the result that moderate numbers of shear bands are formed during deformation. However, low carbon steels, which contain solute carbon, are prone to dynamic strain aging (DSA) at similar temperatures. ${ }^{8)}$ This strongly increases the rate sensitivity of the material, leading to the suppression of shear band formation and thus to a lack of nucleation sites for the $\{111\}$ component. Therefore, the warm rolling of low carbon steels usually results in products with poor formabilities. ${ }^{9)}$

Previous investigations have shown that alloying additions such as chromium and boron can modify the DSA behavior of low carbon steels by extending the DSA peak into the warm rolling temperature region. ${ }^{10,11)}$ This creates a plateau in the flow stress vs. temperature plot, rather than the sharp peak usually associated with conventional carbonnitrogen DSA behavior (Fig. 1). A small increase in strain rate does not then result in a large increase in flow stress within this plateau region, a modification that in turn reduces the rate sensitivity of the material. For example, warm rolled and annealed low carbon steels containing $1.3 \%$ chromium have strong ND fibre texture components, 


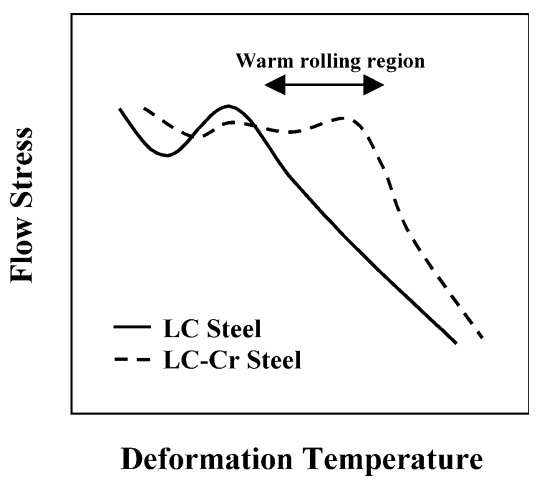

Fig. 1. Effect of chromium addition upon DSA in a LC steel ${ }^{10)}$.

Table 1. Steel compositions (mass\%).

\begin{tabular}{|l|c|c|c|c|c|c|c|}
\hline \multicolumn{1}{|c|}{ Steel } & C & Mn & Cr & Al & N & Ti & B \\
\hline Ti-IF & 0.004 & 0.15 & 0.065 & 0.041 & 0.0037 & 0.062 & - \\
\hline LC & 0.020 & 0.12 & 0.071 & 0.048 & 0.0067 & - & - \\
\hline LCr-HMn & 0.037 & 0.35 & 0.48 & 0.036 & 0.0012 & - & \\
\hline LCr-HMn-B & 0.040 & 0.33 & 0.51 & 0.022 & 0.0045 & 0.014 & 0.0036 \\
\hline LCr-LMn-B & 0.040 & 0.14 & 0.49 & 0.032 & 0.0032 & 0.015 & 0.0039 \\
\hline HCr-LMn-B & 0.040 & 0.15 & 0.80 & 0.037 & 0.0025 & 0.015 & 0.0045 \\
\hline
\end{tabular}

leading to improved formability. ${ }^{12)}$ However, in order to reduce the production cost of such grades, the possibility of using lower levels of chromium, in conjunction with boron addition, was studied in the present work. The effects of manganese content and pre-rolling heat treatment on the warm rolling behavior and product texture were also investigated.

\section{Experimental Procedure}

The chemistries of the steels investigated are listed in Table 1. These included an IF steel stabilized with titanium (Ti-IF) and an unalloyed low carbon (LC) steel, which were regular production alloys. These were received in the form of $100 \mathrm{~mm}$ thick transfer bars from the roughing mill. Four experimental chromium-modified low carbon steels, with two chromium levels $(0.5$ and 0.8 mass $\%)$ and two manganese levels ( 0.15 and 0.33 mass $\%)$, were cast and forged into $50 \mathrm{~mm}$ thick slabs for this project. Titanium and boron additions were also used to modify the DSA behavior, as discussed in detail elsewhere. ${ }^{13)}$ These were made from electrolytic iron to minimize residual elements levels and hence remove any superfluous DSA effects.

Warm rolling was conducted using the pilot mill at CANMET in Ottawa at temperatures between 440 and $780^{\circ} \mathrm{C}$ using a strain rate of $\sim 30 \mathrm{~s}^{-1}$. The surfaces of the rolls were treated with a soluble oil lubricant to minimize friction along the roll gap, since friction can produce a texture gradient through the final product thickness. ${ }^{14)}$ Strips of the Ti-IF and unalloyed LC steels (width $110 \mathrm{~mm}$ ) were reheated in a furnace at $1050^{\circ} \mathrm{C}$ for 30 minutes, whereas the $\mathrm{Cr}$ modified steels were reheated at $950^{\circ} \mathrm{C}$ due to their reduced $\mathrm{A}_{3}$ temperatures. The specimen temperature was monitored using a thermocouple inserted into the center of each strip at its midplane. After austenitization, the steels were air cooled (at approximately $2^{\circ} \mathrm{C} / \mathrm{s}$ ) to the appropriate rolling temperature on a ceramic slab.

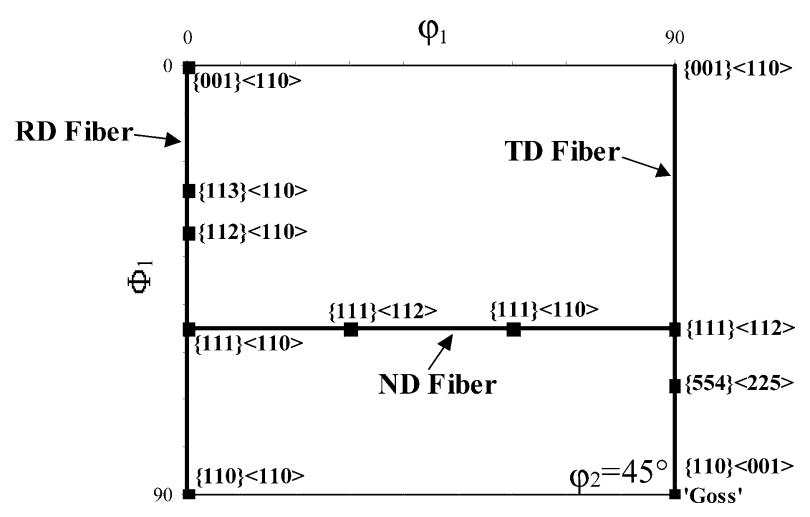

Fig. 2. $\varphi_{2}=45^{\circ}$ plot showing the locations of the main rolling and recrystallization texture components.

All samples were subjected to a reduction of $65 \%$ from an initial thickness of $11 \mathrm{~mm}$ at temperatures of 440,640 , 710 and $780^{\circ} \mathrm{C}$. To minimize interpass recrystallization, single pass rolling was generally used and the sheets were immediately water quenched upon exiting the rolls. In order to reduce the level of solute carbon before rolling, selected samples of the $\mathrm{Cr}$-modified materials were heat treated for $30 \mathrm{~min}$ at $700^{\circ} \mathrm{C}$ prior to rolling (at $640^{\circ} \mathrm{C}$ ). This treatment was expected to have a negligible impact on the grain size whilst allowing near-equilibrium levels of solute carbon to become established. ${ }^{15)}$ The Cr-modified samples were also aged for $6 \mathrm{~h}$ at $450^{\circ} \mathrm{C}$ after rolling, to simulate the effect of sheet coiling. Previous results have shown that this coiling treatment does not affect the properties of the Ti-IF and LC steels. ${ }^{16)}$

Specimens for analysis were cut from the mid-width regions of the as-rolled strips so as to avoid possible edge effects from the rolling process. One sample from each condition was completely recrystallized (determined metallographically and by hardness measurement) using a muffle furnace at 700 to $750^{\circ} \mathrm{C}$ and annealing times of 1 to $12 \mathrm{~h}$. The as-rolled microstructures were analyzed using optical microscopy and the shear band contents quantified using a point counting technique.

Three incomplete pole figures: $\{200\},\{110\}$ and $\{112\}$ were measured along the midplanes of the samples using a Siemens D500 goniometer system (Mo tube) and the standard reflection technique. The orientation distribution functions (ODF's) were calculated from these pole figure data using Bunge's series expansion method ${ }^{17)}$ with an expansion degree of $l_{\max }=22 .{ }^{18)}$ The textures are presented in the reduced $0 \leq \varphi_{1}, \Phi, \varphi_{2} \leq 90^{\circ}$ Euler space due to their cubic crystal and orthorhombic sample symmetries.

It is evident that the textures of warm rolled materials are similar to those of cold rolled products. ${ }^{19)}$ Their ideal fibre orientations in the $\varphi_{2}=45^{\circ}$ section of Euler space are displayed in Fig. 2. These are located along three orientation lines: those having a $\langle 110\rangle$ axis parallel to the rolling direction (the $\alpha$ or RD fibre), those with a $\langle 111\rangle$ axis parallel to normal direction (the $\gamma$ or ND fibre) and those with a $\langle 110\rangle$ axis parallel to transverse direction (the $\varepsilon$ or TD fibre). ${ }^{20)}$ 


\section{Results}

\subsection{Deformation Microstructures}

The as-rolled and quenched microstructures all contained in-grain shear bands. Some of the samples rolled at higher temperatures also exhibited some intergranular nucleation of recrystallized grains (Fig. 3). Shear bands were distributed inhomogeneously between grains and examples of the results obtained are presented in Fig. 4 at a typical warm rolling temperature of $640^{\circ} \mathrm{C}$. It can be seen that in the Ti-IF material, moderately intense shear bands were formed (Fig. 4(a)), but in the LC sample, shear bands of low density and intensity were produced (Fig. 4(b)). By contrast, the four steels with chromium additions contained shear bands of intermediate intensity (Figs. 4(c)-4(e)), with a slightly denser content in the $\mathrm{LCr}-\mathrm{HMn}-\mathrm{B}$ material than in the other three grades.

The fractional shear band contents of the warm rolled steels are summarized in Fig. 5. Note that, at the highest rolling temperature of $780^{\circ} \mathrm{C}$, static recrystallization of the deformed ferrite frequently occurred prior to quenching, leading to a final microstructure of strain-free ferrite with- out any trace of shear bands. It can be seen that the population of shear bands in the Ti-IF steel decreased only slightly with increasing rolling temperature. By contrast, the shear band content of the LC steel displayed a strong de-

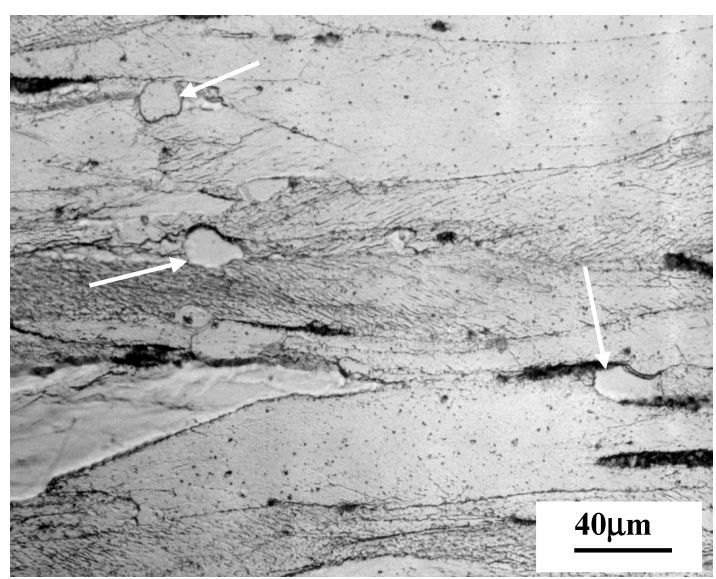

Fig. 3. Shear bands produced in the $\mathrm{HCr}-\mathrm{LMn}-\mathrm{B}$ steel after rolling at $710^{\circ} \mathrm{C}$ (arrows indicate recrystallization nuclei)
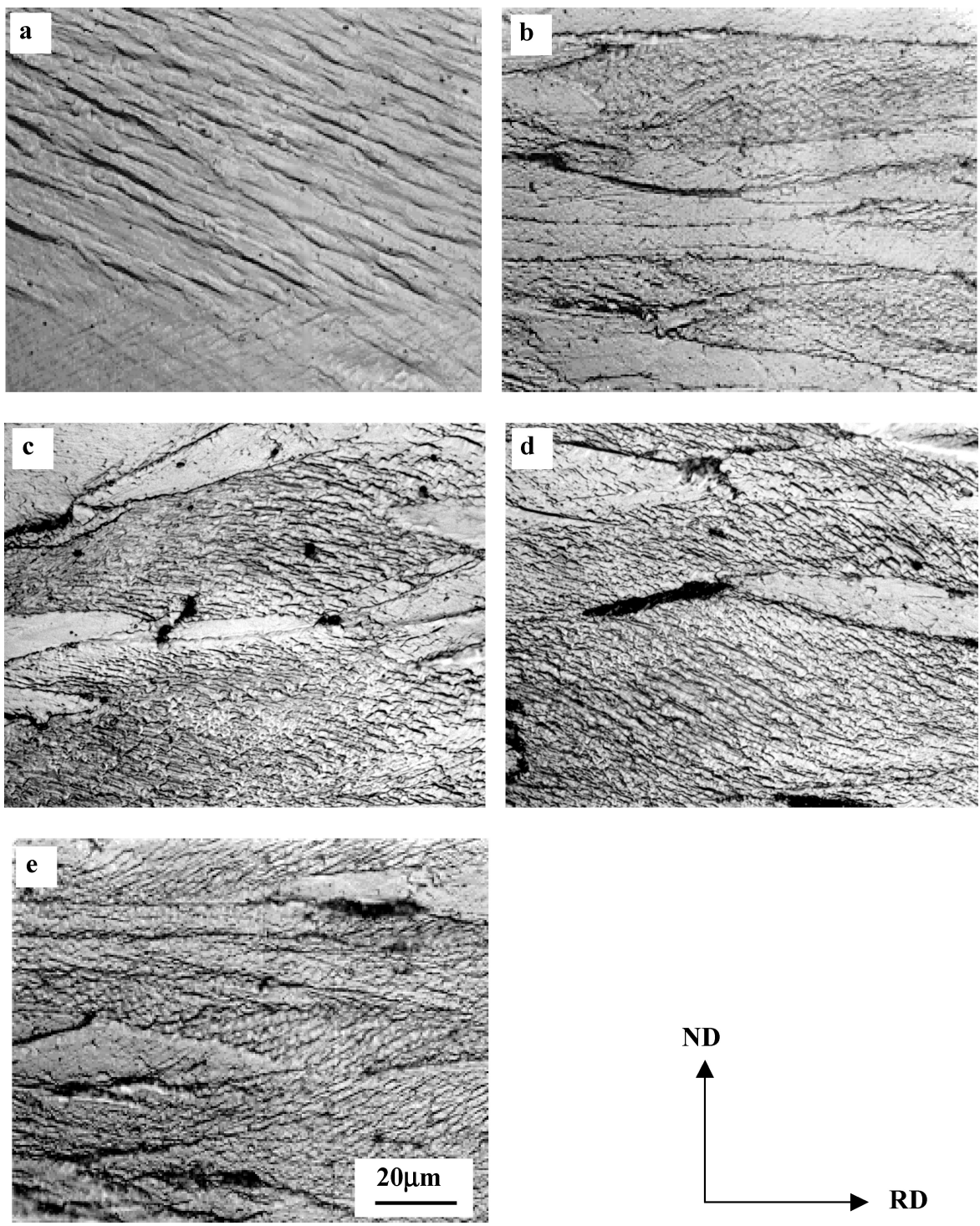

Fig. 4. Typical deformation microstructures produced by rolling at $640^{\circ} \mathrm{C}$ : (a) $\mathrm{Ti}-\mathrm{IF}$; (b) $\mathrm{LC}$; (c) $\mathrm{LCr}-\mathrm{LMn}-\mathrm{B}$; (d) $\mathrm{HCr}-\mathrm{LMn}-\mathrm{B}$ and (e) LCr-HMn-B steel. 
pendence on rolling temperature. Additions of both chromium and boron increased the shear band content at the higher rolling temperatures, thus decreasing the sensitivity to rolling temperature. The steels with the lower manganese level had the highest shear band contents.

The deformation microstructures of the $\mathrm{LCr}-\mathrm{LMn}-\mathrm{B}$ and $\mathrm{HCr}-\mathrm{LMn}-\mathrm{B}$ steels after heat treatment at $700^{\circ} \mathrm{C}$ for 30 min (and subsequent rolling at $640^{\circ} \mathrm{C}$ ) are shown in Fig. 6. This treatment slightly increased the overall shear band population of both materials. It can again be seen that more intense shear bands were formed in the material with the higher chromium content.

\subsection{Deformation Textures}

The deformation textures after rolling at 440, 640 and $710^{\circ} \mathrm{C}$ are presented in Fig. 7. These are typical of ferrite rolling textures, characterized by a partial RD fibre, from $\{001\}\langle 110\rangle$ to $\{111\}\langle 110\rangle$, as well as a complete ND fibre. Although these were all qualitatively similar, higher intensities were present in the LC and LCr-HMn-B steels.

It can be seen that, for the Ti-IF steel, rolling temperature had a limited effect on the intensity of the deformation texture, with an increase from $7 \times$ random at $440^{\circ} \mathrm{C}$ to $10 \times$ random at $710^{\circ} \mathrm{C}$ (Fig. 7(a)). The ND fibre components were dominant at all rolling temperatures and there was a small secondary maximum at the rotated cube component, $\{001\}\langle 110\rangle$.

By contrast, rolling temperature had a significant effect

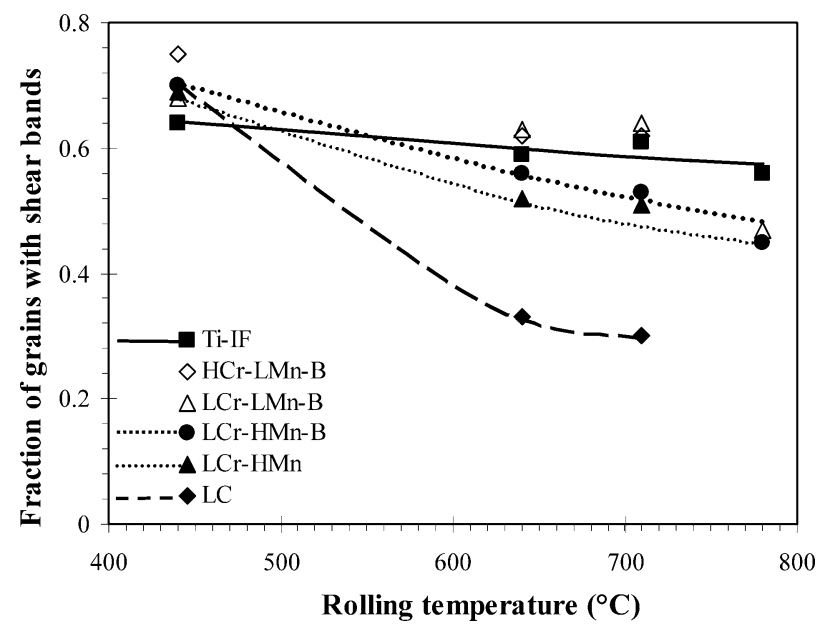

Fig. 5. Dependence of shear band fraction on rolling temperature. on the texture intensity of the low carbon steels, especially the LC material. The maximum intensity in this sample was about $8 \times$ random at $440^{\circ} \mathrm{C}$ and increased to $20 \times$ random at $710^{\circ} \mathrm{C}$ (Fig. 7(b)). The dominant texture component was the rotated cube at all rolling temperatures and there was a secondary maximum along the ND fibre.

Chromium addition decreased the effect of rolling temperature on texture intensity. At the lower level of 0.5 mass \% (LCr-LMn-B, Fig. 7(c)), the maximum texture intensity increased with rolling temperature from $6 \times$ random at $440^{\circ} \mathrm{C}$ to $15 \times$ at $710^{\circ} \mathrm{C}$. It also increased the textural strength of the ND fibre and decreased that of the rotated cube component. At the higher chromium content of 0.8 mass $\%$ (HCr-LMn-B, Fig. 7(d)), the sensitivity to temperature was further decreased. However, the ferrite deformation texture was found to be disrupted by the higher manganese content of the LCr-HMn-B steel (Fig. 7(e)). In this material, the rotated cube reverted to its status as the dominant texture component and the sensitivity to rolling temperature increased.

\subsection{Recrystallization Textures}

To achieve complete recrystallization, the Ti-IF and LC steels were annealed at 750 and $700^{\circ} \mathrm{C}$ for $1 \mathrm{~h}$, respectively. The chromium-modified steels were aged for $6 \mathrm{~h}$ at $450^{\circ} \mathrm{C}$ (to simulate coiling) and then further annealed for $12 \mathrm{~h}$ at $725^{\circ} \mathrm{C}$

The recrystallization textures of the steels annealed after rolling at 440,640 and $710^{\circ} \mathrm{C}$ are illustrated in Fig. 8 . In the Ti-IF material, the ND fibre, $\{111\}\langle 110\rangle$ to $\{111\}\langle 112\rangle$, was dominant at all rolling temperatures and the sharpness remained relatively unchanged with rolling temperature (Fig. 8(a)). By contrast, the recrystallization texture of the LC material varied considerably with temperature (Fig. 8(b)). The dominant component at $440^{\circ} \mathrm{C}$ was the Goss, $\{110\}\langle 001\rangle$, but at higher rolling temperatures, the textures contained a partial RD fibre running from $\{001\}\langle 110\rangle$ to $\{111\}\langle 110\rangle$ with a negligible Goss component. At all temperatures in this material, the ND fibre intensity (which is critical for good formability) was low.

In the chromium-modified steels, the Goss component remained dominant at a rolling temperature of $440^{\circ} \mathrm{C}$ (Figs. $8(\mathrm{c})-8(\mathrm{e}))$. However, the $\{111\}$ ND fibre was significantly strengthened at higher rolling temperatures, although a strong RD fibre, which is detrimental to formability, was also present. The higher chromium content appeared to weaken the RD fibre, although the textural strength of the
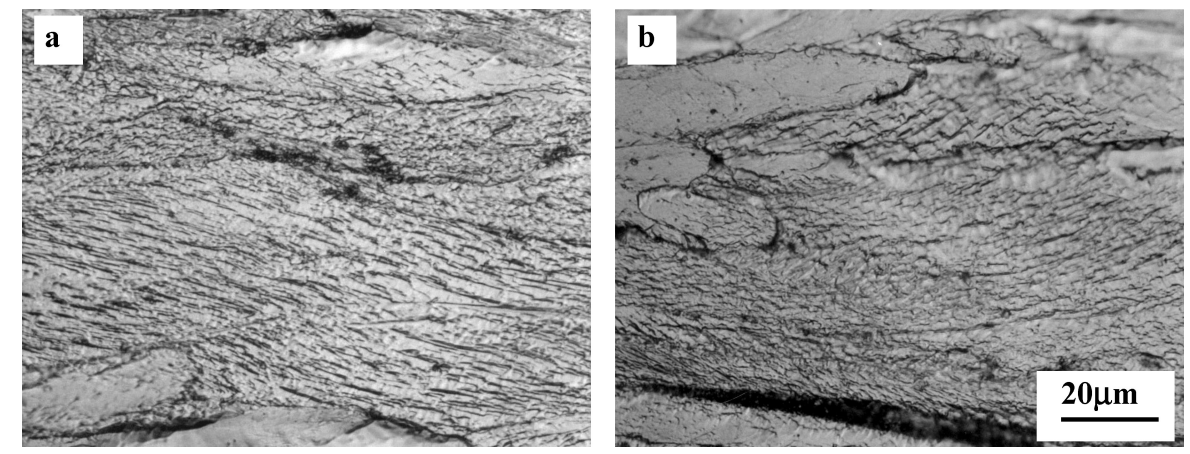

Fig. 6. Shear bands produced in the (a) $\mathrm{LCr}-\mathrm{LMn}-\mathrm{B}$ and (b) $\mathrm{HCr}-\mathrm{LMn}-\mathrm{B}$ steels after heat treatment at $700^{\circ} \mathrm{C}$ for 30 min and then warm rolling at $640^{\circ} \mathrm{C}$. 


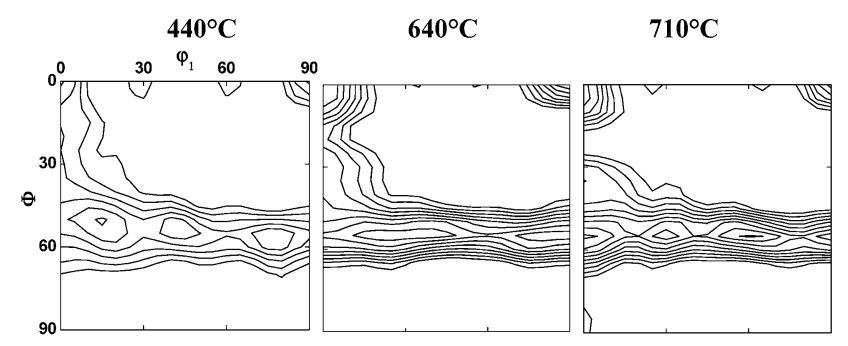

b) LC

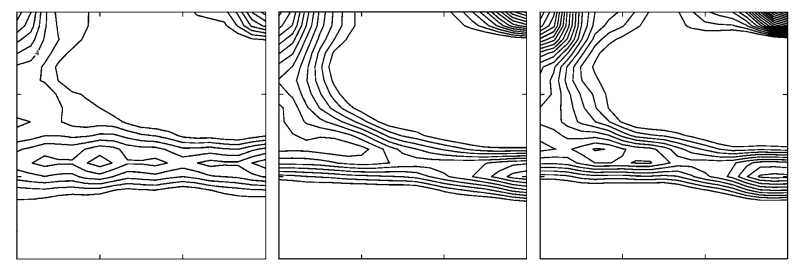

c) LCr-LMn-B

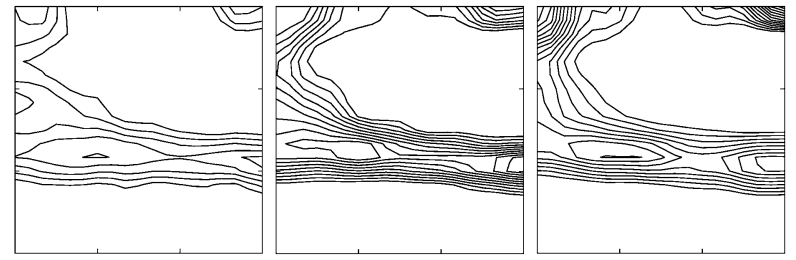

d) $\mathrm{HCr}-\mathrm{LMn}-\mathrm{B}$

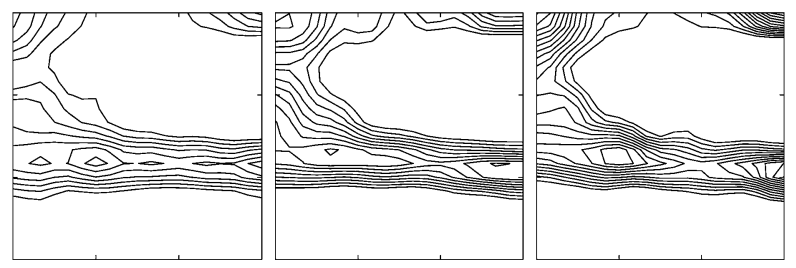

e) LCr-HMn-B
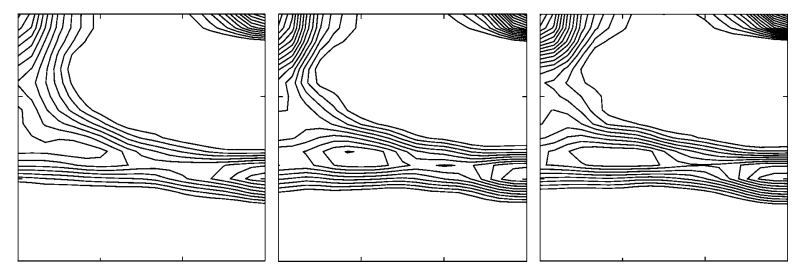

Fig. 7. Deformation textures after rolling at 440,640 and $710^{\circ} \mathrm{C}$ (intensity levels $2,3, \ldots$ ).

ND fibre remained relatively unchanged. The benefits of chromium addition were reversed at the higher manganese level, as this addition weakened the ND fibre and further strengthened the Goss component. The annealing textures of the Cr-modified steels containing boron all contained a significant retained rolling component along the RD fibre. The intensity of this component was appreciably weaker in the steel with no boron addition (Fig. 8(f)).

The recrystallization textures of the chromium-modified steels after a pre-rolling heat treatment $\left(700^{\circ} \mathrm{C}\right.$ for $\left.30 \mathrm{~min}\right)$ are shown in Fig. 9. It can be seen that, with regard to formability, the texture of the $\mathrm{LCr}-\mathrm{LMn}-\mathrm{B}$ material was improved by this treatment, as the textural intensity was more uniform along the ND fibre and the strengths of the other components were reduced (Fig. 9(a)). In the $\mathrm{HCr}-\mathrm{LMn}-\mathrm{B}$ material, the intensity of the ND fibre was actually lower than without heat treatment, although this component was again more uniform (Fig. 9(b)).

\section{Discussion}

\subsection{Effect of Solute Carbon}

It is well known that the solute carbon level has an important effect on the warm rolling behavior of low carbon steels. The dependence of shear band morphology and intensity on rolling temperature in these steels has been described in detail in Ref. 21). Barnett and Jonas ${ }^{1,22)}$ stressed that this dependence can be linked directly to the DSA behaviors of these materials. The interaction between mobile dislocations and solute carbon (and nitrogen) can greatly alter the rate sensitivity of the material, which in turn affects the occurrence of rapid flow localization, i.e. shear banding. At low temperatures, solute carbon reduces the strain rate sensitivity (to a negative value), resulting in prolific in-grain shear banding, whereas at high temperatures, solute carbon increases the rate sensitivity (to a high positive value), thus making it difficult for shear bands to form. ${ }^{11)}$ The rate sensitivities of the steels in this investigation have been studied previously ${ }^{23,24)}$ and are summarized in Fig. 10. Note that these plots were determined at a mean laboratory strain rate of $10^{-2} \mathrm{~s}^{-1}$, so that the temperature 


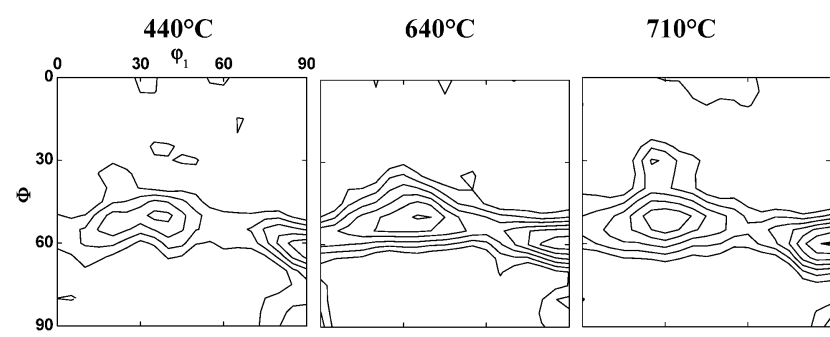

b) LC

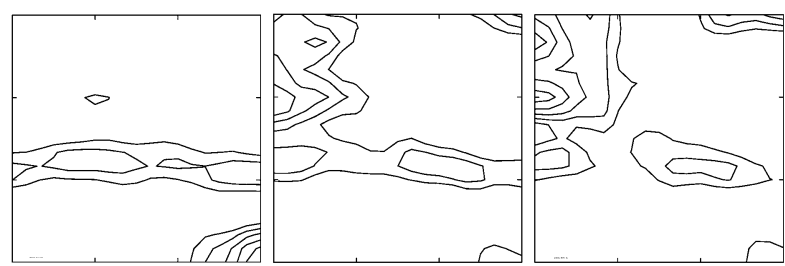

c) LCr-LMn-B

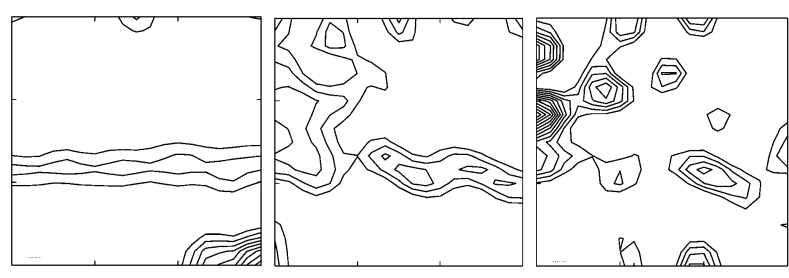

d) HCr-LMn-B

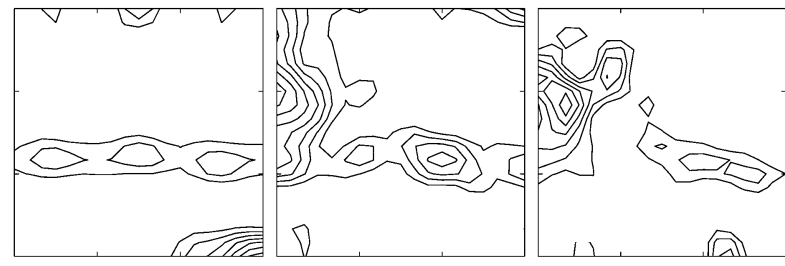

e) LCr-HMn-B

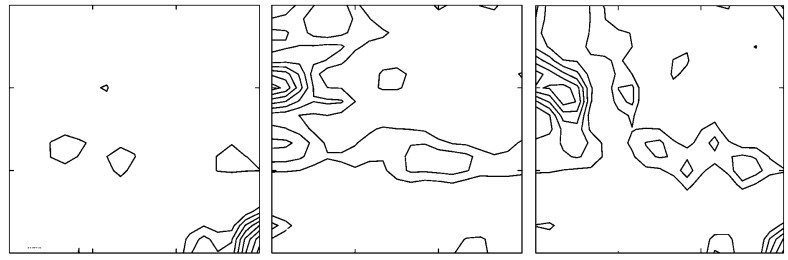

f) LCr-HMn
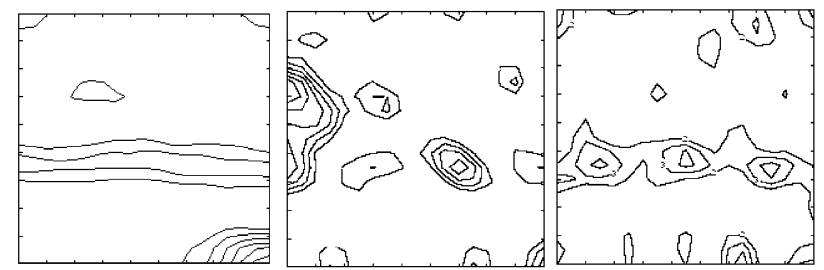

Fig. 8. Recrystallization textures after rolling at 440,640 and $710^{\circ} \mathrm{C}$ (intensity levels $2,3, \ldots$ ).

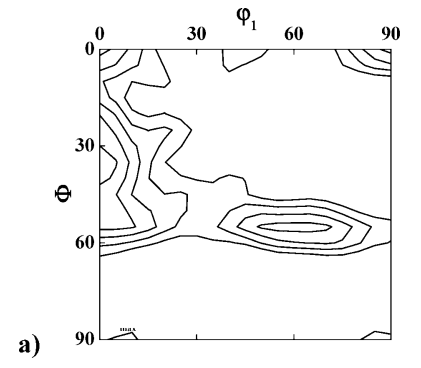

b)

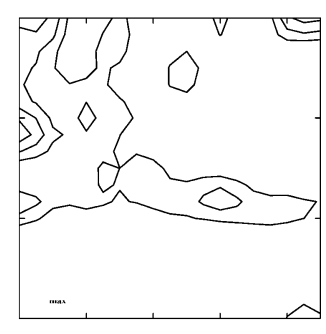

Fig. 9. Recrystallization textures of the (a) LCr-LMn-B and (b) $\mathrm{HCr}-\mathrm{LMn}-\mathrm{B}$ steels after heat treatment at $700^{\circ} \mathrm{C}$ for 30 min and rolling at $640^{\circ} \mathrm{C}$ (intensity levels $2,3, \ldots$ ). axis must be adjusted (using the Zener-Hollomon parameter ${ }^{24)}$ ) for application to sheets rolled at the higher mill strain rate of $30 \mathrm{~s}^{-1}$.

The shear banding behavior significantly affects the deformation textures of these materials. In-grain shear bands transfer strain away from the bulk material, thus reducing the overall degree of matrix rotation compared to that occurring during homogeneous deformation. They also cause fragmentation of the grains, thus further weakening the rolling texture. This is consistent with the deformation textures of the LC steel, whose textural strength increases with rolling temperature due to the decreasing shear band content with increasing temperature. By contrast, in the Ti-IF steel, the shear band population, and hence the deformation texture, does not vary significantly with rolling tempera- 


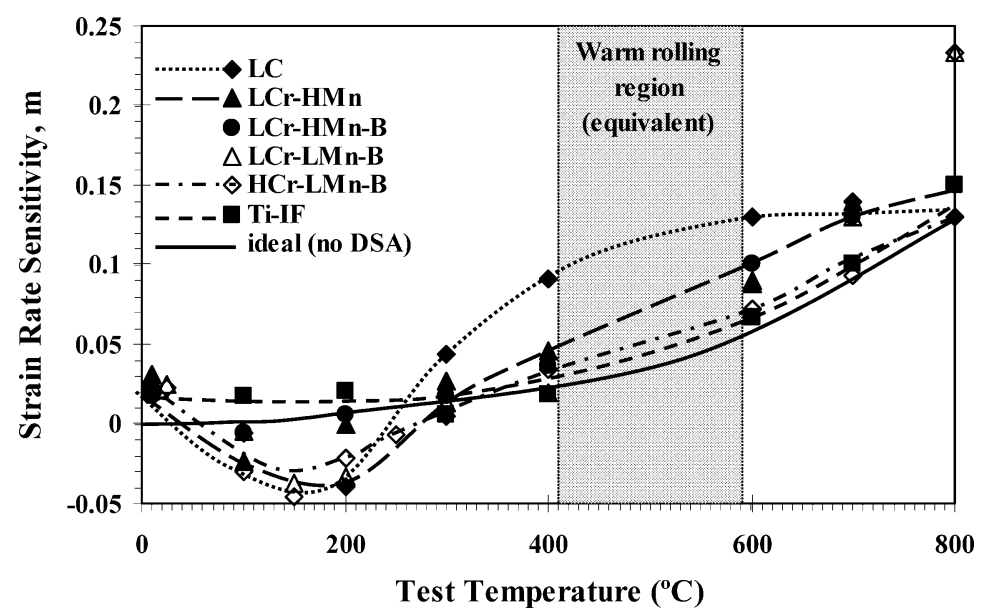

Fig. 10. Dependence of strain rate sensitivity $(m)$ on temperature ${ }^{13,24)}$ (measured at mean strain rate of $10^{-2} \mathrm{~s}^{-1}$ ).

ture.

Shear bands frequently provide preferential nucleation sites for recrystallization; however, the orientations of these nuclei depend on the nature of the shear bands present. When these are of moderate intensity, as in warm rolled Ti-IF steels, recrystallized grains with $\langle 110\rangle \|$ ND type orientations tend to nucleate. $\left.{ }^{6}\right)$ When the bands are intense, as in low carbon steels rolled at lower temperatures in the negative rate sensitivity region, the Goss component $(\{110\}\langle 001\rangle)$ forms in their vicinity. ${ }^{22)}$ This is consistent with the recrystallization textures measured in the present work: a strong ND fibre texture is formed during the recrystallization of the IF steels due to their moderate shear band content. By contrast, in the LC material, the Goss component is formed at the lower rolling temperatures due to the intense shear bands present; at the higher temperatures, on the other hand, insufficient bands are present to nucleate a strong $\{111\}$ texture. Thus the presence of solute carbon during warm rolling is detrimental to the formation of a recrystallization texture with good formability (strong $\{111\}$, weak $\langle 001\rangle$ components).

\subsection{Effect of Chromium Addition}

It has been shown in this work that the addition of chromium to low carbon steels increases the fraction of shear bands formed during warm rolling. This can be linked to the influence of chromium on the DSA behavior and hence on the rate sensitivity. Figure 10 illustrates that in the warm rolling temperature range, where the LC material has a high positive rate sensitivity, the addition of chromium lowers the rate sensitivity to a level close to that of the Ti-IF material. This is due to the formation of a plateau in the flow stress vs. rolling temperature plot, as solute chromium forms a complex of reduced mobility with solute carbon, thus extending the DSA behavior to higher temperatures. $^{23)}$

Due to the increased shear band content at higher rolling temperatures, chromium addition reduced the intensity of the deformation texture (Fig. 7). Note that the rotated cube component present in the $\mathrm{Cr}$-modified steels remained more intense than in the Ti-IF material, presumably because of a difference in their original textures prior to rolling.

The $\{111\}$ fibre of the recrystallization texture was strengthened by chromium addition (Fig. 8), again due to the increase in shear band content, which provides intragranular nucleation sites for this orientation. This fibre was generally of higher intensity in the higher chromium ( $\mathrm{HCr}-\mathrm{LMn}-\mathrm{B})$ than in the lower chromium (LCr-LMn-B) steel. Despite this improvement, when compared with previous work carried out on a $\mathrm{LC}-1.3 \mathrm{mass} \% \mathrm{Cr}$ steel (not containing boron $),{ }^{25)}$ the $\{111\}$ fibres developed by warm rolling and annealing were still not intense enough to produce a sheet of sufficient formability for deep drawing applications. These results indicate that a chromium concentration of $0.8 \%$ is probably insufficient to produce a sharp $\{111\}$ recrystallization texture, at least with the current boron level and under the current processing conditions. For the development of a strong recrystallization texture after ferrite rolling, a sufficient amount of strain energy must be stored in the deformed material. ${ }^{26)}$ It therefore appears likely that the $65 \%$ reduction used in the present work (due to the load limitations of single-pass rolling) produced insufficient stored energy and an insufficiently sharp deformation texture for the production of an ideal annealing texture.

Figure 3 shows that partial recrystallization occurred in the $\mathrm{HCr}-\mathrm{LMn}-\mathrm{B}$ sample during deformation, perhaps due to a slightly higher rolling temperature (mill temperatures clearly have a fairly high degree of experimental error). The volume fraction of recrystallization was small, thus the deformation texture was relatively unaffected. However, the intensity of the ND component of the recrystallization texture was lower than that of the steel with the lower chromium content ( $\mathrm{LCr}-\mathrm{LMn}-\mathrm{B})$, contrary to other results. This effect can be explained in terms of the reduction in stored energy by partial recrystallization of the deformed structure, which in turn weakens the ND fibre produced by recrystallization. This is an important result, as it shows that the recrystallization texture can be significantly disrupted by interpass recrystallization, a phenomenon that must be avoided if warm rolled sheet of high formability is to be produced using multi-pass rolling.

\subsection{Effect of Boron Addition}

In an earlier investigation, ${ }^{13)}$ the addition of boron was found to modify the DSA behavior at warm rolling temperatures so as to decrease the rate sensitivity (Fig. 10). As with chromium addition, this increased the density and in- 
tensity of the shear bands formed during warm rolling and therefore seemed to be a desirable addition. In contrast to the addition of chromium, however, this does not lead to a strengthening of the ND fibre of the annealing texture. Instead, a strong retained rolling component is observed. At present, the origin of this texture component is unclear, but it probably involves the disruption of recrystallization due to the segregation of boron to shear bands as well as grain boundaries. The formation of boron nitrides during annealing is likely to further inhibit recrystallization. These phenomena are currently being studied. Nevertheless, it appears from the results obtained to date that boron additions must be avoided if steels with good formabilities are to be produced by warm rolling.

\subsection{Effect of Manganese Addition}

Previous investigations have shown that manganese addition to low carbon steels modifies the DSA behavior in a manner similar to that of chromium, i.e. the DSA peak is extended into the warm rolling temperature region. ${ }^{10,11)}$ This element is thought to combine with carbon and chromium to form a complex of relatively immobile $\mathrm{C}-\mathrm{Cr}-\mathrm{Mn}$ atoms, which interact with dislocations at higher temperatures than do carbon atoms alone. Indeed, in the present work, the rate sensitivity of the higher manganese steel (LCr-HMn-B) was lower than that of the lower manganese steel ( $\mathrm{LCr}-\mathrm{HMn}-\mathrm{B}$, Fig. 10). Nevertheless, the influence of the higher manganese content on the shear banding behavior differs from that of chromium. Despite the reduction in rate sensitivity, the fractional shear band content was reduced (Fig. 5).

In contrast to the effect of chromium, a high manganese concentration was found to have an adverse affect on the recrystallization texture, weakening the ND fibre and strengthening the Goss component (Fig. 8). This is consistent with previous results that have shown manganese to be detrimental to the development of deep drawing textures in low carbon steels, as it modifies the recrystallization behavior of the material. Carbon-manganese dipoles may encourage the nucleation of unfavorable $\{\mathrm{hkl}\}\langle 110\rangle$ texture components due to an increase in the recrystallization temperature. ${ }^{27)}$ These dipoles have also been observed to retard recovery, ${ }^{28)}$ which again impacts upon the early stages of recrystallization. Manganese is known to affect the texture development as an element in solid solution ${ }^{29)}$ or by interacting with other elements in the steel, such as carbon and nitrogen. ${ }^{30,31)}$ It appears that to develop a warm rolled low carbon steel with good formability, the manganese content must not exceed 0.15 mass $\%$.

\subsection{Effect of Heat Treatment}

The pre-rolling heat treatment $\left(30 \mathrm{~min}\right.$ at $\left.700^{\circ} \mathrm{C}\right)$ was found to strengthen the ND (recrystallization) fibre and hence improve the expected formability of the warm rolled steels (Fig. 9). This can be linked to the increasing intensity of the shear bands attributable to the reduction in the amount of carbon in solution caused by the heat treatment (see Fig. 6). It appears that solute carbon can degrade the recrystallization texture, both during deformation (dynamic strain aging) and annealing (pinning of dislocations by $\mathrm{C}-\mathrm{Mn}$ dipoles). ${ }^{5)}$ Previous workers have shown that solute carbon present during annealing has a more significant ef- fect on the recrystallization texture than during rolling. ${ }^{15)}$ The above results, together with those of the present investigation, ${ }^{16)}$ indicate that heat treatment before annealing (to decrease the level of solute carbon) is more influential than heat treatment before rolling.

\section{Conclusions}

(1) When chromium is added to a low carbon steel containing boron, it somewhat improves the formability of the warm rolled material. This is because the increased shear band concentration promotes the formation of the desirable ND fibre texture.

(2) Although boron addition also reduces the rate sensitivity and increases the shear band content, it is detrimental to the annealing texture, as it creates a retained rolling component that reduces the $r$-value and hence the formability.

(3) A manganese content above 0.15 mass $\%$ has a detrimental effect upon the $\{111\}$ fibre component of the annealing textures of these materials.

(4) Factors such as rolling reduction, interpass recrystallization and pre-rolling and pre-annealing heat treatments have an important impact upon the final annealing texture. More research is necessary to identify the best processing conditions for the achievement of good product formability.

\section{Acknowledgments}

The authors are grateful to Stelco Inc. and Dofasco Inc. for the provision of materials and to Drs. Farid Hassani (Stelco) and Maria-Lynn Turi (Dofasco) for useful discussions. Rolling was conducted at the Materials Technology Laboratory (CANMET) of Natural Resources Canada in Ottawa with the assistance of Claude Galvani. They also acknowledge with gratitude the financial support received from the Natural Sciences and Engineering Research Council of Canada (NSERC). One of the authors (MRT) expresses his thanks to Isfahan University of Technology, Isfahan, Iran for providing a visiting scholarship during which this work was carried out. The provision of additional experimental data by Nadia Romani and Dr. Dongsheng Liu, as well as the help of Edwin Fernandez with testing, are warmly appreciated.

\section{REFERENCES}

1) M. R. Barnett and J. J. Jonas: ISIJ Int., 39 (1999), 856

2) A. Tomiz and R. Kaspar: Steel Res., 71 (2000), 497.

3) W. H. Parks, C. S. Haggerty and T. R. Rock: Iron Steel Eng., (1997), 389.

4) J. J. Jonas: Proc. of Int. Conf. on Processing \& Manufacturing of Advanced Materials, THERMEC 2000, Elsevier Science, UK, (2000), 1.

5) R. K. Ray, J. J. Jonas and R. E. Hook: Int. Mater. Rev., 39 (1995), 129.

6) M. R. Barnett: ISIJ Int., 38 (1998), 78.

7) F. Montheillet and J. J. Jonas: Metall. Mater. Trans., 27A (1996), 3346.

8) A. Karimi Taheri, T. M. Maccagno and J. J. Jonas: ISIJ Int., 35 (1995), 1532.

9) M. R. Barnett and J. J. Jonas: ISIJ Int., 37 (1997), 706.

10) J. Glen: J. Iron Steel Inst., (1957), 21.

11) M. R. Barnett: Modern LC and ULC Sheet Steels for Cold Forming: Processing and Properties, ed. by W. Bleck, Aachen University of Technology, Germany, (1998), 61. 
12) M. R. Barnett: Proc. Of Materials '98, ed. by M. Ferry, IMEA, Australia, (1998), 167.

13) A. O. Humphreys, D. S. Liu, M. R. Toroghinejad and J. J. Jonas: ISIJ Int., 41 (2001), S52.

14) T. Sakai, Y. Saito and K. Kato: Trans. Iron Steel Inst. Jpn., 28 (1988), 1036.

15) M. R. Barnett and L. Kestens: Textures Microstruct., 34 (2000), 1.

16) M. R. Toroghinejad, A. O. Humphreys, D. S. Liu, F. Ashrafizadeh, A. Najafizadeh and J. J. Jonas: Metall. Mater. Trans., 34A (2003), 1163.

17) H. J. Bunge: Texture Analysis in Materials, Butterworths, London, (1982).

18) M. Dahms and H. J. Bunge, J. Appl. Crystallogr., 22 (1989), 439.

19) M. R. Barnett and J. J. Jonas: ISIJ Int., 37 (1997), 697.

20) L. Seidal, M. Holscher and K. Lücke: Textures Microstruct., 11 (1989), 171

21) D. Liu, A. O. Humphreys, M. R. Toroghinejad and J. J. Jonas: ISIJ Int., 42 (2002), 751.

22) J. J. Jonas: Modern LC and ULC Sheet Steels for Cold Forming:
Processing and Properties, ed. by W. Bleck, Aachen University of Technology, Germany, (1998), 73.

23) A. O. Humphreys, D. S. Liu, M. R. Toroghinejad, E. Essadiqi and J. J. Jonas: Mater. Sci. Technol., 19 (2003), 714.

24) N. Romani : M. Eng. Thesis, McGill University, Montreal, Canada, (2003).

25) M. R. Barnett: Steel Res., 71 (2000), 295.

26) T. Nakamura and K. Esaka: Proc. THERMEC 88, TMS-AIME, USA, (1988), 644

27) T. Haratani, W. B. Hutchinson, I. L. Dillamore and P. Bate: Met. Sci., 18 (1984), 57.

28) W. B. Hutchinson and K. Ushioda: In Proc. 7th Int. Conf. on Textures of Materials, Noordwijkerhout, Netherlands Society for Mat. Sci., Netherlands, (1984), 409.

29) H. Hu and S. R. Goodman: Metall. Trans., 1 (1970), 3057.

30) I. F. Hughes and E. W. Page: Metall. Trans., 2 (1971), 2067.

31) H. Hu: Metall. Trans., 8A (1977), 1567. 